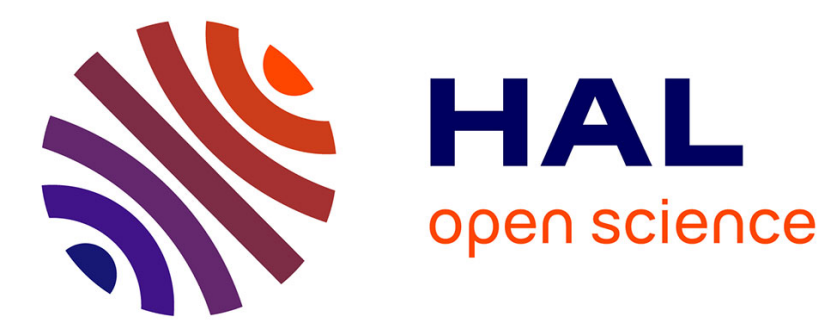

\title{
The liver receptor homolog-1 regulates estrogen receptor expression in breast cancer cells
}

\author{
Paul T. R. Thiruchelvam, Chun-Fui Lai, Hui Hua, Ross S. Thomas, Antoni \\ Hurtado, William Hudson, Andrew R. Bayly, Fiona J. Kyle, Manikandan \\ Periyasamy, Andrew Photiou, et al.
}

\section{To cite this version:}

Paul T. R. Thiruchelvam, Chun-Fui Lai, Hui Hua, Ross S. Thomas, Antoni Hurtado, et al.. The liver receptor homolog-1 regulates estrogen receptor expression in breast cancer cells. Breast Cancer Research and Treatment, 2010, 127 (2), pp.385-396. 10.1007/s10549-010-0994-9 . hal-00594480

\section{HAL Id: hal-00594480 \\ https://hal.science/hal-00594480}

Submitted on 20 May 2011

HAL is a multi-disciplinary open access archive for the deposit and dissemination of scientific research documents, whether they are published or not. The documents may come from teaching and research institutions in France or abroad, or from public or private research centers.
L'archive ouverte pluridisciplinaire HAL, est destinée au dépôt et à la diffusion de documents scientifiques de niveau recherche, publiés ou non, émanant des établissements d'enseignement et de recherche français ou étrangers, des laboratoires publics ou privés. 
The Liver Receptor Homolog $1(\mathrm{LRH}-1)$ Regulates Estrogen Receptor Expression in Breast Cancer Cells

Paul T. R. Thiruchelvam ${ }^{a}$, Chun-Fui Lai ${ }^{a}$, Hui Hua ${ }^{a}$, Ross S. Thomas ${ }^{a}$, Antoni Hurtado $^{\mathrm{b}}$, William Hudson ${ }^{\mathrm{c}}$, Andrew R. Bayly ${ }^{\mathrm{d}}$, Fiona J. Kyle ${ }^{\mathrm{a}}$, Manikandan Periyasamy $^{\mathrm{a}}$, Andrew Photiou ${ }^{\mathrm{a}}$, Alan C. Spivey ${ }^{\mathrm{d}}$, Eric A. Ortlund ${ }^{\mathrm{c}}$, Richard J. Whitby $^{\mathrm{e}}$, Jason S. Carroll ${ }^{\mathrm{b}}$, R. Charles Coombes ${ }^{\mathrm{a}}$, Laki Buluwela ${ }^{\mathrm{a} 1}$, Simak $\mathrm{Ali}^{\mathrm{a} 1}$

aDept of Oncology, Imperial College London, Hammersmith Hospital, Du Cane Road, London W12 ONN, UK.

${ }^{b}$ Cancer Research UK, Cambridge Research Institute, Li Ka Shing Centre, Robinson Way, Cambridge CB2 ORE, UK.

${ }^{\mathrm{C} D e p t}$ of Biochemistry, Emory University School of Medicine, Atlanta, GA 30322, USA.

dDept of Chemistry, Imperial College London, South Kensington Campus, Exhibition Road, London SW7 2AZ, UK.

${ }^{\text {e}}$ School of Chemistry, University of Southampton, Highfield, Southampton, SO17 1BJ, UK.

Author Contributions: R. C. C., L. B. and S. A. conceived all experiments. P. T. R. T., C-F. L., H. H., M. P., A. P., F. J. K. and R. S. T. performed all experiments. A. B., A. C. S and R. J. W generated LRH-1 activators. R. S. T., W. H. and E. A. O. conceived and performed the in vitro DNA binding studies. 
A. H. and J. S. C. conceived and performed the ChIP experiments. S. A. wrote the manuscript with advice from all authors.

The authors declare no conflict of interest.

${ }^{1}$ To whom correspondence may be addressed: I.buluwela@imperial.ac.uk or simak.ali@imperial.ac.uk.

Keywords: estrogen, estrogen receptor, gene regulation, $\mathrm{LRH}-1$ 


\section{Abstract}

Purpose: Estrogen receptor- $(E R)$ is expressed in the great majority of breast cancers and inhibition of ER action is a key part of breast cancer treatment. Inhibition of ER action is achieved using anti-estrogens, primarily tamoxifen, and with aromatase inhibitors that inhibit estrogen biosynthesis and thereby prevent ER activation. However, resistance to these therapies is common. Towards identifying new molecular targets for breast cancer therapy, we have identified LRH-1 as an estrogen-regulated gene. The aim of this study was to determine the importance of $\mathrm{LRH}-1$ in breast cancer cells.

Methods: RNA interference and over-expression studies were used to investigate the role of $\mathrm{LRH}-1$ in regulating breast cancer growth and to identify the targets of $\mathrm{LRH}-1$ action. Promoter recruitment was determined using reporter gene and chromatin immunoprecipitation (ChIP) assays.

Results: We show that $\mathrm{LRH}-1$ regulates breast cancer cell growth by regulating ER expression. Reporter gene and in vitro DNA binding assays identified an LRH-1 binding site in the ER gene promoter and ChIP assays have demonstrated in vivo binding at this site. We also provide evidence for new LRH-1 variants in breast cancer cells arising from the use of alternative promoters.

Conclusions: Previous studies have shown that $\mathrm{LRH}-1$ functions in estrogen biosynthesis by regulating aromatase expression. Our findings extend this by highlighting $\mathrm{LRH}-1$ as a key regulator of the estrogen response in breast cancer cells through the regulation of ER expression. Hence inhibition of LRH- 
1 could provide a powerful new approach for the treatment of endocrine resistant breast cancer. 


\section{Introduction}

Estrogen plays a critical role in the development and progression of breast cancer. Its actions are mediated by estrogen receptors, with estrogen receptor- (ER) being expressed in the majority of breast cancers. ER is a member of the nuclear receptor (NR) superfamily of transcription factors that acts by regulating specific gene expression upon binding estrogen. Inhibition of ER activity is achieved clinically through the use of selective estrogen receptor modulators (SERMs), such as tamoxifen, that compete with estrogen for binding to ER, to inhibit its activity $[1,2]$. Aromatase inhibitors act by inhibiting the conversion of androgens into estrogen and provide an alternative and effective approach for inhibiting ER activity, with newly introduced aromatase inhibitors, such as Anastrozole and Letrozole, already proving to have greater efficacy than tamoxifen $[3,4]$.

The regulation of ER gene expression has been subjected to intense study due to its important role in regulation of breast cancer and other important physiological processes such as cardiovascular protection, bone homeostasis and osteoporosis, and sexual development in males and females [5]. The coding region of the ER gene is located within 8 exons spanning $140 \mathrm{~kb}$ on chromosome 6q25 [6, 7]. Regulation of ER gene expression is complex, with transcription being initiated within multiple promoters spanning $150 \mathrm{~kb}$ [8]. Several of these promoters show tissuespecificity [9], which has further complicated studies to define the transcriptional regulators of ER gene expression.

Liver receptor homologue (LRH-1), like $\mathrm{ER}$, is a member of the NR superfamily. It belongs to the Ftz-f1 or NR5A subfamily that includes 
steroidogenic factor-1 (SF-1), members of which are characterised by the presence of an extended DNA binding domain (DBD), the so-called Ftz-F1 box located at the C-terminus of the DBD [10]. Most NRs bind to DNA sequences conforming to the consensus NR binding sequence, AGGTCA, either as homodimers (e.g. ER) to palindromes of the AGGTCA motif or to direct repeats of the AGGTCA motif as heterodimers with retinoid $\mathrm{X}$ receptor(RXR ) [11]. By contrast, members of the Ftz-F1 subfamily bind to sequences having a 5' extension to the NR DNA binding motif as monomers, with the FtzF1 box targeting the 5'-YCA extension to the NR DNA binding motif [12], where $\mathrm{Y}$ is $\mathrm{C}$ or $\mathrm{T}$. Until recently classified as orphan receptors, structural studies have shown that LRH-1 and SF-1 bind phosphatidyl inositols, with their binding being required for maximal activity [13-15]. LRH-1 plays important roles in metabolism, being involved in the regulation of reverse cholesterol transport, lipid and cholesterol absorption, bile acid homeostasis and steroidogenesis [10]. In particular, LRH-1 has been implicated in the regulation of aromatase (CYP19) expression in the ovary [16]. Interestingly, in adipose tissue from normal women, CYP19 expression is low and mainly originates from the use of promoter I.4. By contrast, in breast cancer adipose tissue activation of additional CYP19 gene promoters is seen, including importantly, the gonadal PII promoter. In the latter context, $\mathrm{LRH}-1$ regulates CYP19 expression through binding to a response element in the PII promoter [17-20].

In the present study, we show that in breast cancer cells $\mathrm{LRH}-1$ is coexpressed with ER in breast cancer cell lines and that RNAi mediated $\mathrm{LRH}-1$ knock-down inhibits breast cancer cell growth. We demonstrate that this is 
due, at least in part, to regulation of ER expression by $\mathrm{LRH}-1$ through direct binding to the ER gene promoter. These studies show for the first time, that $E R$ is an $L R H-1$ target gene, a finding that is potentially relevant for the development of new therapies for breast cancer. 


\section{Materials and Methods}

Cell lines. COS-1, MCF-7, T47D, ZR75-1, BT474 and MDA-MB-231 cells were routinely cultured in DMEM containing 10\% FCS. For estrogen-depletion experiments, the cells were transferred to DMEM lacking phenol red and containing $5 \%$ dextran-coated charcoal-stripped FCS for 72 hours, as described previously [21]. 17ß-estradiol (estrogen), 4-hydroxytamoxifen and $\mathrm{ICI} 182,780$ were prepared in ethanol and added to the medium at a final concentration of $10 \mathrm{nM}$ (estrogen) or $100 \mathrm{nM}$ (4-hydroxytamoxifen, ICI 182, 780). Compounds 5A, 5B and 5L, which have previously been described [25], were prepared in DMSO and added to a final concentration of $10 \mu \mathrm{M}$.

Plasmids. The renilla luciferase reporter gene was RLTK (Promega, UK). $\mathrm{LRH}-1$ and SHP expression was from pCl-LRH-1, pCDM8-hSHP and the LRH-1 firefly luciferase reporter gene was SF-1-luc (gifts from Dr Donald McDonnell and Dr David Moore) [14]. The F342W/I416W LRH-1 mutant was generated by site-directed mutagenesis of $\mathrm{pCl}-\mathrm{LRH}-1$ using primers having the sequences

CAAGCACGAAAAGCTGAGCACCTGGGGGCTTATGTGCAAAA-3' and 5'ACTGGGCAACAAGTGGACTATTCCATATGGGCATCACAAGCCGG-3'. The PII-516 aromatase reporter gene was kindly provided by Drs Colin Clyne and Evan Simpson. ERP-Luc was generated by amplifying the genomic region covering the ER gene promoter A to LRHRE3 (-5993/-117) using high fidelity pfu DNA polymerase (Fermentas, UK) with DNA prepared from the human ER gene Bacterial Artificial Chromosome clone RP3-443C4 (Geneservice Ltd, UK). The PCR product was cloned into pJET (Fermentas, UK) (pJET-ERP) and re-cloning of into the pGL3-Basic luciferase reporter vector (Invitrogen), 
following digestion with Bglll restriction enzyme. The three putative LRH-1 response elements in this region, LRHRE1-3, were mutated by site-directed mutagenesis (Quickchange; Stratagene), changing the $\mathrm{LRH}-1$ binding site to a BamHI restriction site in each case (details available on request).

Transfections. MCF-7 and BT474 cells were transiently transfected with 100 ng of SHP or $50 \mathrm{ng}$ of $\mathrm{LRH}-1$ and total RNA and protein lysates were prepared 48 hours later, as described [21]. For reporter gene assays, COS-1 cells were transiently transfected in 96-well plates, using FuGene HD (Roche), according to manufacturer's protocols. The cells were transfected with $25 \mathrm{ng}$ of the pGL3-Promoter based reporter plasmids or $100 \mathrm{ng}$ of the pGL3-Basic, SF-1 Luc and RLTK, together with $50 \mathrm{ng}$ of pCl-LRH-1. Cells were lysed 24 hours following transfection and firefly and renilla luciferase activities determined using the Dual Glo system (Promega, UK). A similar method was used for assaying ERP-luc and PII-516 aromatase reporter genes in COS- 1 or MCF-7 cells.

siRNA. Cells were transfected using Lipofectamine RNAiMAX, according to manufacturer's methods (Invitrogen). RNA and protein were prepared 48 hours following transfection. Cell number was estimated using the sulphorhodamine B (SRB) growth assay, as described previously [40]. siRNA LRH-1 On-TargetPlus Smartpool (Dharmacon) comprised siRNAs having the sequences: 5'-CAUAAUGGGCUAUUCAUAU-3'

$(\# 1)$, 5 AGAGAAAUUUGGACAGCUA-3' (\#2), 5'-GGAGUGAGCUCUUAAUCCU-3' (\#3) and 5'-GAAGCCAUGUCUCAGGUGA-3' (\#4). siGenome non-targeting siRNA (Dharmacon) had sequences 5'-UAAGGCUAUGAAGAGAUAC-3', 5'- 
AUGUAUUGGCCUGUAUUAG-3'， 5'-AUGAACGUGAAUUGCUCAA-3', 5'UGGUUUACAUGUCGACUAA-3'.

RT-PCR. Total RNA was collected and real-time RT-PCR was performed as previously described [40]. Real-time RT-PCR was carried out using Taqman Gene Expression Assays (Applied Biosystems, UK) for ER (ESR1; Hs00174860_m1), CTD (Hs00157201_m1), LRH-1 (Hs00187067_m1), pS2 (TFF1; Hs00170216_m1), SHP (Hs00222677_m1), Dax1 (Hs00230864_m1), SF-1 (Hs00610436_m1) and GAPDH (Hs99999905_m1) on an ABI 7900HT machine.

Western blotting. Cells were cultured and protein lysates prepared as described previously [21]. Antibodies used were anti-ER (Novacastra Laboratories), anti-LRH-1 (Perseus Protemics). SHP, cathepsin D and B-actin antibodies were purchased from Abcam.

ChIP. ChIP was performed as previously described [41]. Antibody used was LRH1 and primers for real time PCR were: LRHRE1 Fwd 5'CTAGCCCAAGTGAACCGAGA-3', LRHRE1 Rev 5'ACCTCAGGTCACGAACCAAA-3'. For normalization qPCR was performed for previously described control region for the c-myc gene, as described previously [23], using oligonucleotides having the sequences: c-myc Fwd 5'GCCAGTCCAACCGGCTTATG-3', c-myc Rev 5'GGTTCTCCCAAGCAGGAGCA-3'.

In vitro DNA binding Assay. Binding affinities for $L R H-1$ binding to LRHRE1 sequences were obtained using a fluorescence polarization assay, following expression and purification of LRH-1 amino acid residues 79-184 as a MBP fusion protein in E. coli, as described previously [12]. Carboxyfluorescin 
(FAM) labeled duplex oligonucleotides based on the LRHRE1 sequence 5'-AATTGCCAAAGCTTTGGT-3' and the CYP7A1 LRH-1 binding site (described previously [12] (Integrated DNA Technologies, USA), were used. 10nM of FAM-labeled oligonucleotide was mixed with MBP-LRH-1 DBD at varying concentrations, and polarization was measured in milli-polarization units (mP). The experiments were performed on a Panvera Beacon 2000, with an excitation wavelength of $495 \mathrm{~nm}$, and an emission wavelength of $520 \mathrm{~nm}$. The results were analyzed by SigmaPlot to generate binding data and dissociation constants. 


\section{Results}

\section{LRH-1 Regulates the Growth of Breast Cancer Cells.}

As a strategy to identify key estrogen-regulated genes in breast cancer cells, we modified the estrogen-responsive and ER positive MCF-7 breast cancer cell line, to conditionally express a transcriptionally repressive ER, PLZF-ER, composed of the PLZF transcriptional repressor fused to the ER DNA and ligand binding domains [21]. The resulting line grows in an estrogendependent manner in the absence of PLZF-ER expression, but induction of PLZF-ER expression blocks its growth. Gene expression microarray analysis carried out using this line, identified 1,627 genes which showed $>1.5$-fold regulation by estrogen within 16 hours. Of these genes, 149 were repressed by PLZF-ER, suggesting that these genes are important for estrogenregulated growth of MCF-7 cells (Buluwela et al., in preparation). One of the 149 genes whose expression was repressed by PLZF-ER in MCF-7 cells was $\mathrm{LRH}-1$. Estrogen treatment of MCF-7 cells showed a four-fold increase in LRH-1 expression (Fig. 1A), confirming the microarray findings; no stimulation of $\mathrm{LRH}-1$ expression was observed when the cells were treated with the antiestrogens 4-hydroxytamoxifen or ICI182, 780. Further, LRH-1 expression was considerably higher in ER-positive, compared with ER-negative lines (Fig. 1B), suggestive of an association between ER expression and $\mathrm{LRH}-1$ expression in breast cancer cells.

Analysis of the ER binding and Polll occupancy data generated from ChIP-chip and ChIP-seq profiling of global ER and Polll binding following treatment of estrogen-depleted MCF-7 cells with estrogen for 1 hour $[22,23]$ 
showed ER binding to a region $10.5 \mathrm{~kb}$ upstream from the $\mathrm{LRH}-1$ exon 1 . Real-time PCR of ChIP following estrogen treatment of MCF-7 cells confirmed that estrogen stimulates ER binding to this region of the $\mathrm{LRH}-1$ promoter (Fig. 1D).

Several LRH-1 splice variants have been described [10, 24], including $\mathrm{hLRH}-1$ and $\mathrm{LRH}-1 \mathrm{v} 2$ both of which lack exon 2 encoded amino acids 22-67 (Fig. 2B). In performing immunoblotting for $\mathrm{LRH}-1$, we noted that many of the commercially available antibodies, whilst detecting transfected $\mathrm{LRH}-1$ did not detect $\mathrm{LRH}-1$ in breast cancer lines. As these antibodies were directed to the $\mathrm{LRH}-1 \mathrm{~N}$-terminus, we wondered if this was due to the predominance of exon 2 deleted $\mathrm{LRH}-1$ variants in these lines. 5'-rapid amplification of complementary DNA ends (5'-RACE) for defining 5' ends of $\mathrm{LRH}-1$ transcripts in MCF-7 cells identified three main forms (Fig. 2A), the well-described LRH-1 variant 1 (v1) encoding a polypeptide of 541 amino acids, and two new variants, which we named variant 4 (v4) and variant 5 (v5) to distinguish them from the previously described $\mathrm{LRH}-1$ variants. V4 and v5 would be expected to encode polypeptides of 501 and 482 amino acids, respectively. Interestingly, $\mathrm{LRH}-1-\mathrm{v} 4$ transcription is initiated in intron 1 of the $\mathrm{LRH}-1$ gene, extending the previously identified exon 2 further 5 ' into intron 1 (named exon 2a) (Fig. 2C; supplementary Fig. 1). The mapped 5' end of LRH-1-v5 defined an exon in intron 2 (here named exon $2 b$ ). Hence, v4 and v5 define transcripts from previously undescribed, alternative $\mathrm{LRH}-1$ gene promoters. Blast searching of the $\mathrm{NCBI}$ database (http://blast.ncbi.nlm.nih.gov/Blast.cgi) identified one EST clone, TRACH3028697 (GenBank number: DC418114.1; the $5^{\prime}$ end of which precisely matched the 5' end determined by 5'-RACE. 
Also identified was an EST clone that contained the sequences present in v4 and extended the $5^{\prime}$ untranslated region by a further $87 \mathrm{bp}$ (Fig. 2B). No corroborating evidence for v5 was found in EST databases.

Expression analysis using isoform-specific real-time RT-PCR showed that $v 4$ and v5 are highly estrogen-regulated, whereas variants $h L R H-1, v 1$ and v2 expression were weakly stimulated by estrogen in MCF-7 cells (Fig. 3A). Note that using these primer sets we did not distinguish between hLRH$1, \mathrm{v} 1$ and v2. Furthermore, RT-PCR and immunoblotting showed that $\mathrm{v} 4$ is the predominant form of $\mathrm{LRH}-1$ expressed in breast cancer cell lines (Fig. 3B, C). However, extensive reporter gene analysis did not reveal a significant difference between LRH-1 v1 and v4 (data not shown; Fig. 3D), despite the fact that $\mathrm{v} 4$ lacks the $\mathrm{N}$-terminal 40 amino acids present in $\mathrm{v} 1$.

RNA interference (RNAi) used to determine if $\mathrm{LRH}-1$ is an important mediator of estrogen-stimulated growth of MCF-7 cells, showed that LRH-1 down-regulation using a pool of 4 small interfering RNAs (siRNA) potently inhibited MCF-7 growth (Fig. 4A). The individual siRNAs all inhibited MCF-7 growth, with the least growth inhibition being observed for siRNA \#1, the siRNA that gave the smallest reduction in LRH-1 expression (Supplementary Fig. 2, Fig. 4B, 4F). Transfection with $\mathrm{LRH}-1$ siRNAs also inhibited the growth of the LRH-1 positive ZR-75-1 and T47D cells, but growth of the LRH-1 negative cell lines BT474 and MDA-MB-231 was unaffected by LRH-1 siRNA (Supplementary Fig. 3A).

LRH-1 Regulates Estrogen Receptor Expression in Breast Cancer Cells. 
Determination of the expression of estrogen-regulated genes showed that $\mathrm{LRH}-1$ knockdown reduced expression of the pS2 and cathepsin D (CTD) genes (Fig. 4C, D), prompting us to determine whether the growth inhibitory effects of LRH-1 knockdown could be due to LRH-1 regulation of ER expression. Indeed, ER mRNA and protein were reduced following siRNA for LRH-1 (Fig. 4E, F). Inhibition of ER expression following LRH-1 knockdown was also observed in T47D and ZR75-1 cells (Supplementary Fig. 3B, C).

In order to confirm these findings, we investigated whether synthetic LRH-1 activating compounds could stimulate MCF-7 cell growth. A number of substituted cis-bicyclo[3.3.0]-oct-2-enes have been identified as small molecule agonists of LRH-1 and SF-1 [25]. As there was no detectable expression of SF-1 in MCF-7 and BT-474 cells (Supplementary Fig. 4), we determined the effect of three of these compounds $(5 A, 5 B$ and $5 L)$ on cell growth. MCF-7 cell growth was stimulated, whereas growth of the ER-positive but LRH-1 negative BT-474 cells was unaffected (Fig. 5A). As seen with a reporter gene assay, these compounds stimulated the activity of an LRH-1 responsive luciferase reporter gene (Fig. 5B) and treatment with the compounds increased ER levels in MCF-7 cells (Fig. 5C). Moreover, LRH-1 transfection stimulated ER expression in MCF-7 and BT474 cells (Fig. 5D, E), whereas transfection of the small heterodimer partner (SHP), a NR that acts as a co-repressor for LRH-1 [26] reduced ER expression in MCF-7 cells (Figure 5F, G). Further, transfection of LRH-1 stimulated the growth of MCF-7 cells, whilst SHP inhibited LRH-1 growth (Fig. 5H). 


\section{LRH-1 Regulates ER expression by Direct Recruitment to the ER Gene}

Promoter. Expression of the human ER gene is initiated at multiple promoters spanning $150 \mathrm{~kb}$ [8]. RT-PCR showed that in the lines examined, the majority of ER expression is initiated at promoters $A, B$ and $C$, with some expression from promoter F (Fig. 5A; supplemental Fig. 5). Analysis of the region encoding ER gene promoters $A$ through $F$ revealed the presence of 11 sequences conforming to the LRH-1 consensus binding site (YCAAGGYCR [27]), with the closest of these sites being located less than $6 \mathrm{~kb} 5$ to promoters A/B (Fig. 6A). Additionally, our analysis highlighted an extended palindrome centred around a HinDIII restriction enzyme site (5'CCAAAGCTTTGG-3'), which encoded a sequence (underlined) similar to that identified in the mouse SEBP gene as an LRH-1 binding site [28], 912 bp 5 ' to the promoter A start site (named LRHRE1).

As promoters $\mathrm{A}$ and $\mathrm{B}$ constitute the major promoters utilised in MCF-7 cells we generated an ER promoter luciferase reporter gene (ERP-luc) encoding a $6.0 \mathrm{~kb}$ region comprising promoters $A$ through $\mathrm{D}$ and containing two putative LRH-1 binding sites (LRHRE2, LHRRE3) that conform to the $\mathrm{LRH}-1$ consensus binding site sequence, as well as LRHRE1. The ERP-luc reporter was activated by LRH-1 in MCF-7 cells (Fig. 6B). Structural studies have shown that the $\mathrm{LRH}-1$ ligand binding domain (LBD) has phospholipids bound [13-15]. An LRH-1 mutant ( $\mathrm{LRH}-1-\mathrm{F} 342 \mathrm{~W} / \mathrm{l} 416 \mathrm{~W})$, which is impaired for phospholipid binding and shows reduced transcriptional activity [14] also showed reduced activation of ERP-luc. Mutation of LRHRE2 and LRHRE3 had modest effects on $\mathrm{LRH}-1$ regulation of the reporter gene, with a considerably larger reduction in reporter gene activity being observed if 
LRHRE1 was mutated (Fig. 6C), suggesting that $\mathrm{LRH}-1$ binds to the LRHRE1 sequence.

As the LRHRE1 sequence does not conform to the LRH-1 consensus binding site, binding of $\mathrm{LRH}-1$ to this sequence was determined using a fluorescence polarization assay using $E$. coli expressed $L R H-1$ DBD and FAM-labelled oligonucleotides. The Kd of LRH-1 binding to LRHRE1 (126 nM) was similar to that obtained for the $\mathrm{LRH}-1$ site in the Cyp7A1 gene promoter (200 nM) (Fig. 6D; supplemental Fig. 5).

ChIP analysis of MCF-7 cell lysates with an LRH-1 antibody showed $\mathrm{LRH}-1$ recruitment to the region of the ER promoter containing the LRHRE1 sequence (Fig. 6E). Taken together, these findings indicate that the $\mathrm{LRH}-1$ is recruited to the LRHRE1 sequence in the ER gene promoter and that this sequence is important for $\mathrm{LRH}-1$ regulation of $\mathrm{ER}$ expression. 


\section{Discussion}

\section{$\mathrm{LRH-1}$ is an estrogen-regulated gene in breast cancer cells}

Estrogens play critical roles in the initiation and progression of human breast cancer, as well as other gynaecological cancers. Estrogen actions are mediated by ER, which acts primarily as a transcription factor that, upon binding estrogen, regulates the expression of large numbers of estrogenresponsive genes [29], resulting in the case of breast cancer cells, to inhibition of apoptosis and promotion of proliferation. Defining the key estrogenregulated genes in cancer cells would provide important insights into the mechanisms by which estrogen/ER promotes breast cancer growth. Using an engineered MCF-7 cell line that conditionally expresses a dominant-negative form of ER in which the PLZF transcriptional repressor was fused to ER [21], we identified $\mathrm{LRH}-1$ as a gene whose expression was repressed upon expression of the PLZF-ER. RT-PCR analysis and immunoblotting confirmed estrogen-regulation of $\mathrm{LRH}-1$, as has previously been described [30]. As also described previously siRNA mediated LRH-1 silencing potently inhibited the estrogen-stimulated growth of MCF-7 cells. Moreover, we observed inhibition of the growth of other ER/LRH-1 positive breast cancer cell lines (ZR75-1, T47D).

The study by Annicotte et al [30] previously identified an estrogen response element $2.3 \mathrm{~kb}$ upstream of the LRH-1 exon 1. ChIP based global analysis of ER binding sites did not, however, detect significant binding to this region in MCF-7 and ZR75-1 cells. Instead binding to a region $10.5 \mathrm{~kb}$ upstream of exon 1 was seen in both cell lines. This region contains the 
sequence 5'-AGGaCAcacTGACCT-3' (starting at chromosome 1 bp $198,252,853$ in the NCBI hg18 human genome release, in which exon 1 of the $\mathrm{LRH}-1$ gene is at bp 198,263,393 (http://genome.ucsc.edu)), which conforms well to the consensus ERE sequence (AGGTCAnnnTGACCT) [31]. ChIP analysis confirmed estrogen-stimulated ER recruitment to this site, indicating that this site is involved in ER regulation of $\mathrm{LRH}-1$ expression.

\section{A new LRH-1 variant is the predominant form of $\mathrm{LRH}-1$ in breast cancer cells}

$\mathrm{LRH}-1$ transcript mapping identified two new $\mathrm{LRH}-1$ variants, both of which are expressed from distinct new promoters, one initiating within intron 1 and extending exon 2127 bp 5' (v4), the second initiating in intron 2 and lacking exon 1 and 2 sequences (v5). Both of these variants are estrogen regulated, but v5 expression is low in breast cancer cells. $\mathrm{LRH}-1-\mathrm{v} 1$ was the only other variant whose expression was observed by $5^{\prime}$-RACE, but it was also expressed at low levels, with v4 being the major form of $\mathrm{LRH}-1$ in breast cancer cells, which was confirmed by immunoblotting. Forms of $\mathrm{LRH}-1$ corresponding to $\mathrm{v} 4$, as well as $\mathrm{v} 1$ are seen in the mouse, chicken (Supplementary Fig. 1B, C) and rat, while v4 corresponds to the $\mathrm{LRH}-1$ transcripts predicted to come from the xenopus and zebrafish $\mathrm{LRH}-1$ genes. Furthermore, analysis of the ChIP-chip for RNA polymerase II (PollI) [22] showed that at the $\mathrm{LRH}-1$ locus the strongest binding of Polll is centred on exon 2 sequences (see Fig. $2 \mathrm{C}$ ), which indicates that in MCF-7 cells the major transcription initiation sites for $\mathrm{LRH}-1$ are centred around exon 2. Finally, realtime RT-PCR using RNA from a panel of human tissues showed that v4 is 
expressed more widely than the other variants. Indeed, we did not detect expression of the other variants in the absence of v4 expression. Taken together, these findings provide strong evidence for the in vivo importance of $\mathrm{LRH}-1-\mathrm{v} 4$. A previous study examining $\mathrm{LRH}-1$ expression immunohistochemically in invasive ductal carcinoma showed that $43 \%$ of breast tumours are $\mathrm{LRH}-1$ positive [32], expression being negatively associated with clinical stage and histological status and positively associated with steroid receptor status. As this study was carried out using an antibody directed to amino acids 2-33 of LRH-1-v1 (absent in v4), it is possible that $\mathrm{LRH}-1$ positivity was underestimated, highlighting the need for re-evaluation of $\mathrm{LRH}-1$ in breast cancer, the lack of currently ascribed differences in the activities of $\mathrm{LRH}-1$ variants 1 and 4 notwithstanding. As the antibodies available to us have proved to be unsuitable for immunohistochemistry, we are currently developing new antibodies to address this issue.

\section{LRH-1 Regulates Estrogen Receptor Expression in Breast Cancer Cells}

$\mathrm{LRH}-1$ knockdown inhibits breast cancer cell growth, as previously described [30] and confirmed here. Importantly, LRH-1 knockdown reduced ER expression, $\mathrm{LRH}-1$ over-expression or stimulation of its activity by synthetic agonists increased ER levels, whilst the LRH-1 repressor SHP reduced ER expression. Reporter gene studies and mutational analysis showed that three sites contribute to $\mathrm{LRH}-1$ regulation of the ER reporter gene, with an LRH-1 binding site, named LRHRE1 (5'-AATTGCCAAAGCTTTGGT-3') having a sequence similar to the LRH-1 binding site in the mouse SEBP gene (5'-CCCAAAGGCTT-3') [28] being the 
most important site for $\mathrm{LRH}-1$ regulation of ER expression. Finally, ChIP confirmed binding of $\mathrm{LRH}-1$ to the ER gene in a region encompassing this site. Taken together, these results show that $\mathrm{LRH}-1$ regulates ER-positive breast cancer cell growth through a mechanism involving regulation of ER gene expression through direct recruitment to the ER promoter.

Previous work has highlighted a positive regulatory loop in which ER and GATA-3 reciprocally regulate each other in breast cancer cells [33], and provides a possible explanation for the co-expression of ER and GATA-3 in breast cancers (for refs. see [33, 34]. Other estrogen regulated genes have been shown to be important for ER action in breast cancer cells, with FoxA1 being required for the recruitment of ER to the promoters of many estrogenresponsive genes [35, 36]. Our findings show that ER and $\mathrm{LRH}-1$ form a positive cross-regulatory loop in which each transcription factor is required for the expression of the other gene.

The aromatase (CYP19) gene is transcribed from a number of different promoters, with expression from the different promoters being highly tissue selective. The aromatase promoter II (PII) is used in gonadal tissues and its regulation by SF-1 has been demonstrated [37-39]. Whilst in normal breast tissue, aromatase is expressed at low levels, with promoter 1.4 being utilised, in tumour bearing breast tissue, aromatase expression is elevated, with transcription being driven largely through PII promoter [19]. These studies have also indicated that SF-1 is not expressed in breast tumours, whilst LRH-1 is expressed in adipose tissue, with co-expression of LRH-1 and aromatase being evident particularly in pre-adipocytes [17]. In this context, $\mathrm{LRH}-1$ regulates aromatase expression thorugh recruitment to the PII 
Promoter [17, 18]. Furthermore, regulation of the PII promoter by $\mathrm{LRH}-1$ occurs synergistically with GATA3 [18]. Interestingly, regulation of ER expression by GATA3 has also previously been described [33]. Our preliminary analysis shows that $\mathrm{LRH}-1$ and GATA3 also act synergistically at the ER promoter (Supplementary Figure 7). Aromatase expression is additionally dependent on tumour-derived growth factors, particularly prostaglandin $E_{2}$, acting through protein kinase $A(P K A)$ to stimulate aromatase PII activity $[17,18]$. In agreement with these findings, activity of the aromatase PII reporter gene was strongly increased by PKA, whereas PKA did not similarly potentiate the synergism between LRH-1 and GATA3 at the ER gene promoter (Supplementary Figure 7). Together, these results indicate that aromatase and ER expression are similarly regulated, albeit in different cell types, indicating that the cell-type specificity may be due to differences in cell signalling pathways, such as those involving PKA (for potential model of aromatase and ER regulation by $\mathrm{LRH}-1$ see Supplementary Figure $7 \mathrm{C})$.

Of course, differential expression of $\mathrm{LRH}-1$ variants may also be important in specifying cell-type selectivity for the differential regulation of aromatase and ER genes in different cell types. Furthemore, we did not observe expression of the $\mathrm{LRH}-1$ regulated SHP gene in the breast cancer cell lines. Nor was Dax1 expression evident in $\mathrm{LRH}$ - positive breast cancer lines. As SHP and Dax1 are important regulators of $\mathrm{LRH}-1$ activity [26], their presence or absence may also be important in defining promoter and celldependent activities of $\mathrm{LRH}-1$, as well as responses to other signalling pathways, such as PKA. 
In conclusion, our studies show that $\mathrm{LRH}-1$ is a key regulator of estrogen responses in breast cancer, which acts by regulating estrogen synthesis in breast tumour tissue and by regulating ER expression in breast cancer cells. As such, $\mathrm{LRH}-1$ presents as an important target for the development of new therapeutic agents for use in breast cancer treatment. 


\section{Acknowledgements}

We would like to thank D. McDonnell, D. D. Moore, J. J. Tremblay, R. S. Viger, C Clyne, E. R. Simpson and S. Wang for kind gifts of plasmids and A. G. M. Barrett, M. Fuchter and A. Jaxa-Chamiec for helpful discussions. We also thank A. M. Khan for help with bioinformatics analysis of the ER gene sequences. This work was supported by grants from Cancer Research UK, the Royal College of Surgeons, the Wellcome Trust and the Department of Health funded Imperial College Cancer Medicine Centre (ECMC) grant. We are also grateful for support from the NIHR Biomedical Research Centre funding scheme. 


\section{References}

1. Osborne, C.K., Tamoxifen in the treatment of breast cancer. $\mathrm{N}$ Engl J Med, 1998. 339(22): p. 1609-1618.

2. Ali, S. and R.C. Coombes, Endocrine-responsive breast cancer and strategies for combatting resistance. Nature Rev. Cancer, 2002. 2: p. 101-112.

3. Johnston, S.R. and M. Dowsett, Aromatase inhibitors for breast cancer: lessons from the laboratory. Nat Rev Cancer, 2003. 3(11): p. 821-831.

4. Chen, S., et al., What do we know about the mechanisms of aromatase inhibitor resistance? J Steroid Biochem Mol Biol, 2006. 102(1-5): p. 232-40.

5. Couse, J.F. and K.S. Korach, Estrogen receptor null mice: what have we learned and where will they lead us? Endocr Rev, 1999. 20(3): p. 358-417.

6. Ponglikitmongkol, M., S. Green, and P. Chambon, Genomic organization of the human oestrogen receptor gene. Embo J, 1988. 7(11): p. 3385-8.

7. Gosden, J.R., P.G. Middleton, and D. Rout, Localization of the human oestrogen receptor gene to chromosome 6q24----q27 by in situ hybridization. Cytogenet Cell Genet, 1986. 43(3-4): p. 218-20.

8. Flouriot, G., et al., Differentially expressed messenger RNA isoforms of the human estrogen receptor-alpha gene are generated by alternative splicing and promoter usage. Mol Endocrinol, 1998. 12(12): p. 1939-54.

9. Kos, M., et al., Minireview: genomic organization of the human ERalpha gene promoter region. Mol Endocrinol, 2001. 15(12): p. 205763.

10. Fayard, E., J. Auwerx, and K. Schoonjans, LRH-1: an orphan nuclear receptor involved in development, metabolism and steroidogenesis. Trends Cell Biol, 2004. 14(5): p. 250-60.

11. Mangelsdorf, D.J., et al., The nuclear receptor superfamily: the second decade. Cell, 1995. 83(6): p. 835-9.

12. Solomon, I.H., et al., Crystal structure of the human LRH-1 DBD-DNA complex reveals Ftz-F1 domain positioning is required for receptor activity. J Mol Biol, 2005. 354(5): p. 1091-102.

13. Krylova, I.N., et al., Structural analyses reveal phosphatidyl inositols as ligands for the NR5 orphan receptors SF-1 and LRH-1. Cell, 2005. 120(3): p. 343-55.

14. Ortlund, E.A., et al., Modulation of human nuclear receptor $L R H-1$ activity by phospholipids and SHP. Nat Struct Mol Biol, 2005. 12(4): p. 357-63.

15. Wang, W., et al., The crystal structures of human steroidogenic factor-1 and liver receptor homologue-1. Proc Natl Acad Sci U S A, 2005. 102(21): p. 7505-10.

16. Mendelson, C.R., et al., Transcriptional regulation of aromatase in placenta and ovary. J Steroid Biochem Mol Biol, 2005. 95(1-5): p. 2533. 
17. Clyne, C.D., et al., Liver receptor homologue-1 (LRH-1) regulates expression of aromatase in preadipocytes. J Biol Chem, 2002. 277(23): p. 20591-7.

18. Bouchard, M.F., H. Taniguchi, and R.S. Viger, Protein kinase Adependent synergism between GATA factors and the nuclear receptor, liver receptor homolog-1, regulates human aromatase (CYP19) PII promoter activity in breast cancer cells. Endocrinology, 2005. 146(11): p. $4905-16$.

19. Clyne, C.D., et al., Regulation of aromatase expression by the nuclear receptor $L R H-1$ in adipose tissue. Mol Cell Endocrinol, 2004. 215(1-2): p. 39-44.

20. Kovacic, A., et al., Inhibition of aromatase transcription via promoter II by short heterodimer partner in human preadipocytes. Mol Endocrinol, 2004. 18(1): p. 252-9.

21. Buluwela, L., et al., Inhibiting estrogen responses in breast cancer cells using a fusion protein encoding estrogen receptor-alpha and the transcriptional repressor PLZF. Gene Ther, 2005. 12(5): p. 452-60.

22. Carroll, J.S., et al., Genome-wide analysis of estrogen receptor binding sites. Nat Genet, 2006. 38(11): p. 1289-97.

23. Ross-Innes, C.S., et al., Cooperative interaction between retinoic acid receptor-alpha and estrogen receptor in breast cancer. Genes Dev, 2010. 24(2): p. 171-82.

24. Nitta, M., et al., CPF: an orphan nuclear receptor that regulates liverspecific expression of the human cholesterol 7alpha-hydroxylase gene. Proc Natl Acad Sci U S A, 1999. 96(12): p. 6660-5.

25. Whitby, R.J., et al., Identification of small molecule agonists of the orphan nuclear receptors liver receptor homolog-1 and steroidogenic factor-1. J Med Chem, 2006. 49(23): p. 6652-5.

26. Lee, Y.K. and D.D. Moore, Dual mechanisms for repression of the monomeric orphan receptor liver receptor homologous protein-1 by the orphan small heterodimer partner. J Biol Chem, 2002. 277(4): p. 24637.

27. Ueda, $\mathrm{H}_{\text {., }}$ et al., $A$ novel DNA-binding motif abuts the zinc finger domain of insect nuclear hormone receptor FTZ-F1 and mouse embryonal long terminal repeat-binding protein. Mol Cell Biol, 1992. 12(12): p. 5667-72.

28. Song, X., et al., Liver receptor homolog 1 transcriptionally regulates human bile salt export pump expression. J Lipid Res, 2008. 49(5): $p$. 973-84.

29. Frasor, J., et al., Profiling of estrogen up- and down-regulated gene expression in human breast cancer cells: insights into gene networks and pathways underlying estrogenic control of proliferation and cell phenotype. Endocrinology, 2003. 144(10): p. 4562-74.

30. Annicotte, J.S., et al., The nuclear receptor liver receptor homolog-1 is an estrogen receptor target gene. Oncogene, 2005. 24(55): p. 8167-75.

31. Klinge, C.M., Estrogen receptor interaction with estrogen response elements. Nucleic Acids Res, 2001. 29(14): p. 2905-19.

32. Miki, Y., et al., Immunolocalization of liver receptor homologue-1 (LRH1) in human breast carcinoma: possible regulator of insitu steroidogenesis. Cancer Lett, 2006. 244(1): p. 24-33. 
33. Eeckhoute, J., et al., Positive cross-regulatory loop ties GATA-3 to estrogen receptor alpha expression in breast cancer. Cancer Res, 2007. 67(13): p. 6477-83.

34. Kouros-Mehr, H., et al., GATA-3 and the regulation of the mammary Iuminal cell fate. Curr Opin Cell Biol, 2008. 20(2): p. 164-70.

35. Carroll, J.S., et al., Chromosome-wide mapping of estrogen receptor binding reveals long-range regulation requiring the forkhead protein FoxA1. Cell, 2005. 122(1): p. 33-43.

36. Laganiere, J., et al., From the Cover: Location analysis of estrogen receptor alpha target promoters reveals that FOXA1 defines a domain of the estrogen response. Proc Natl Acad Sci U S A, 2005. 102(33): $p$. 11651-6.

37. Michael, M.D., et al., Ad4BP/SF-1 regulates cyclic AMP-induced transcription from the proximal promoter (PII) of the human aromatase P450 (CYP19) gene in the ovary. J Biol Chem, 1995. 270(22): p. 13561-6.

38. Carlone, D.L. and J.S. Richards, Functional interactions, phosphorylation, and levels of 3',5'-cyclic adenosine monophosphateregulatory element binding protein and steroidogenic factor-1 mediate hormone-regulated and constitutive expression of aromatase in gonadal cells. Mol Endocrinol, 1997. 11(3): p. 292-304.

39. Young, M. and M.J. McPhaul, A steroidogenic factor-1-binding site and cyclic adenosine 3',5'-monophosphate response element-like elements are required for the activity of the rat aromatase promoter in rat Leydig tumor cell lines. Endocrinology, 1998. 139(12): p. 5082-93.

40. Lopez-Garcia, J., et al., ZNF366 is an estrogen receptor corepressor that acts through CtBP and histone deacetylases. Nucleic Acids Res, 2006. 34(21): p. 6126-36.

41. Schmidt, D., et al., ChIP-seq: using high-throughput sequencing to discover protein-DNA interactions. Methods, 2009. 48(3): p. 240-8. 


\section{Figure Legends}

Fig. 1. $\mathrm{LRH}-1$ is an estrogen-regulated gene that functions in breast cancer cell growth. (A) Hormone-depleted MCF-7 cells were stimulated with vehicle, estrogen, tamoxifen or ICl182780 and LRH-1 mRNA levels were assessed by real-time RT-PCR (lower panel). Protein lysates prepared following stimulation of hormone-depleted MCF-7 cells were immunoblotted (upper panel). (B) LRH-1 and ER mRNA levels were determined by real-time RTPCR analysis of total RNA. (C) Shown is the LRH-1 locus with the positions of ER binding regions (black box) and RNA Polll occupancy for MCF-7 cells treated with estrogen for 1 hour. Also shown is the region of ER binding for ZR75-1. Shown are the ER and PollI occupancy representations, generated by uploading the ChIP-Seq datasets to the UCSC genome browser gateway

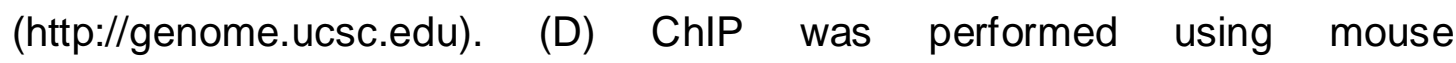
immunoglobulins (IgG) or an ER antibody, and quantitative PCR was carried out for the ER binding site identified in (C). PCR for a region in intron 3 served as a negative control for ER binding. The results of three independent replicates are shown.

Fig. 2. Identification of new $\mathrm{LRH}-1$ variants in breast cancer cells. (A) Products of 5'-RACE are shown for RNA prepared from MCF-7 cells treated with estrogen (E2) or vehicle (NL) for 8 hours. The products were cloned and sequenced to assign their identities, as marked. (B) Shown is a schematic representation of $\mathrm{LRH}-1$ variants, including variants v4 and v5 identified here. (C) Sequence of LRH-1 variants v4 and v5. The DNA sequences in italics represent the 5' untranslated regions present in the 5'-RACE cloning 
products. The sequences in lower case shown for the $\mathrm{v} 4$ are present in an EST (UTERU3011183) (http://www.ncbi.nlm.nih.gov/). The underlined amino acids in v5 are the amino acids arising from the newly described exon (exon 2b).

Fig. 3. $\mathrm{LRH}-1$ variant 4 is the major form of $\mathrm{LRH}-1$ in breast cancer cells. (A) LRH-1 variant mRNA levels in MCF-7 cells were determined by real-time RTPCR using primers that specifically amplify v4 or v5 sequences. Primers for v1/v2 amplify LRH-1 variants 1 and 2 , as well as $h L R H-1$. The results for three independent RNA samples are shown, with in each case expression level in the absence of ligand (NL) being taken as 1 and expression level in the presence of E2 shown relative to that. (B) Expression of $\mathrm{LRH}-1$ variants in breast cancer cell lines is shown. Expression of v1/v2 in MCF-7 was taken as 1 and all other values are shown relative to this. (C) Protein lysates prepared from breast cancer lines and COS-1 cells transfected with LRH-1 v1 or v4 were immunoblotted for $\mathrm{LRH}-1$ and B-actin. (D) COS-1 cells were cotransfected with an $\mathrm{LRH}-1$ responsive luciferase reporter gene (SF-1-luc) and increasing amounts of LRH-1 v1 or v4. Reporter gene activities are shown relative to the vehicle control. Protein lysates prepared from these lysates were immunoblotted for $\mathrm{LRH}-1$ to determine relative expression of the variants (lower panel).

Fig. 4. Targeted knockdown of LRH-1 inhibits Estrogen Receptor (ER) expression. (A) MCF-7 cells grown in estrogen-depleted medium were transfected with LRH-1 siRNA, treated with vehicle or estrogen and cell 
number estimated after 4 days using the sulphorhodamine B (SRB) assay. Growth is shown relative to the reagent alone control for three experiments. (B-E) siRNA pool for LRH-1 or individual siRNAs were transfected into MCF-7 cells, RNA and protein was prepared after 48 hours. LRH-1 (B), pS2 (C) cathepsin D (CTD) (D) and ER (E) mRNA levels were determined by real-time RT-PCR analysis. Shown are the means and s.e.m. for three experiments. Asterisks show statistically significant difference (unpaired t-test, $p<0.05$ ) from the reagent or non-targeting controls. (F) Immunoblotting was performed following preparation of protein lysates from MCF-7 cells transfected with siRNAs for LRH-1.

Fig. 5. LRH-1 stimulates Estrogen Receptor (ER) expression in breast cancer cells. (A) Hormone-depleted MCF-7 and BT-474 cells were stimulated with vehicle, estrogen or $\mathrm{LRH}-1$ activators over a 12-day period. Shown is growth at day 12 , relative to the vehicle control, as measured using the SRB assay. (B) COS-1 cells transfected with an $\mathrm{LRH}-1$ responsive luciferase reporter gene (SF-1-luc) were stimulated with vehicle (DMSO) or $\mathrm{LRH}-1$ activators $5 \mathrm{~A}$, 5B and 5L. Reporter gene activities are shown relative to the vehicle control. (C) RNA was prepared from MCF-7 cells treated with compounds $5 \mathrm{~A}, 5 \mathrm{~B}$ and $5 \mathrm{~L}$ for 8 hours. ER mRNA levels were determined by real-time RT-PCR. (D, G) Protein lysates prepared from MCF-7 cells following transfection with LRH1 (D) or SHP (G) were immunoblotted. (E, F) Real-time RT-PCR was performed using RNA prepared from MCF-7 cells transfected with $\mathrm{LRH}-1$ (E) or SHP (F). (H) MCF-7 cells were transiently transfected with LRH-1 or SHP and cell numbers estimated after 4 days using the SRB assay. Growth is 
shown relative to the vector control. All graphical results are shown as the means and s.e.m relative to the vehicle or vector controls, of at least three replicates. Asterisks denote statistically significant difference $(p<0.05)$ relative to the appropriate vehicle or vector control, determined using the unpaired t-test.

Fig. 6. $L R H-1$ binds to a specific site within the ER gene promoter. (A) Shown is a schematic representation of the ER gene, with the positions of ER promoters A through $\mathrm{F}$ highlighted. Transcription start site positions shown are as previously described [9]. Sequences that are similar to the consensus $\mathrm{LRH}-1$ binding site are shown, either above or below the rectangle, with the sequences shown below the rectangle to denote that the site maps on the lower DNA strand, whilst those above the rectangle represent sites on the upper DNA strand. The region of the ER gene used to generate the ER promoter luciferase reporter gene (ERP-luc) is shaded. (B) MCF-7 cells were transfected with ERP-luc, together with LRH-1 or the LRH-1-F342W/I416W mutant. (C) Reporter gene activities were determined for MCF-7 cells transfected with ERP-luc, or mutants in which LRHRE1-3 were mutated. All reporter gene activities are shown as the means and s.e.m, for three replicates, relative to the vector control. (D) DNA binding to LRHRE1 and the Cyp7A1 LRH-1 response element was measured by changes in fluorescence polarization for the LRH-1 DBD. The results of at least three replicates are shown. (E) ChIP was performed using lysates prepared from MCF-7 cells, and real-time PCR for three replicates using primers for a control region (CTCF) and the ER promoter encompassing LRHRE1, are shown. In all cases 
asterisks show statistically significant differences $(p<0.05)$, determined using the unpaired t-test, between sample 1 and the other samples, or relative to the control samples. 


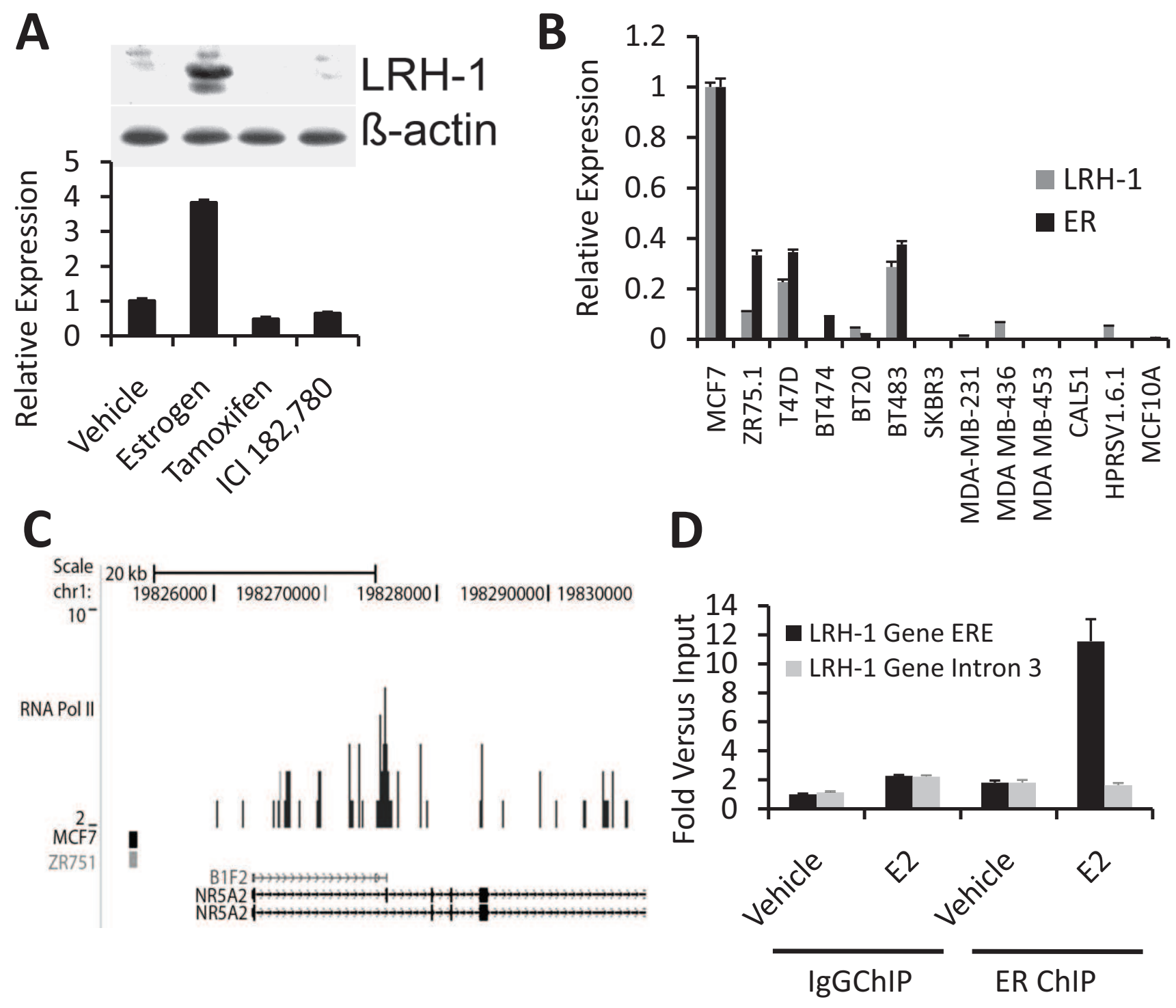


Figure 2

Click here to download Figure: Thiruchelvam et al Figure_2.pptx

A

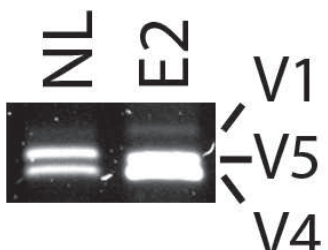

B AF-1 DBD Hinge LBD/AF-2

LRH-1v1 $\square 40$

hLRH-1 - $\square 495$

LRH-1v2 - $\square 323$

LRH-1v4 $\square 01$

LRH-1v5 482

C

\section{LRH-1 V4}

Exon $2 a$

1 aggtcctgcccggcagccccgaggaggcggaggcacgctccggcgaggcg

51 agagggttgggttagcaggcatcccggtcgccccttcCTTCTTTTCGCCG

101 GAGTTGAATCTGTGCTGCCCGTGTCCAGGTGCTGGGCTTCCGGACCGACA

151 CGGATCCCCCATCCCCGCCCGCGGTCGCCTTGTCATGCTGCCCAAAGTGG $\begin{array}{lllll}M & L & P & K & V\end{array}$

201 AGACGGAAGCCCTGGGACTGGCTCGATCGCATGGGGAACAGGGCCAGATG

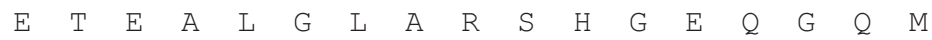

Exon 3

251 CCGGAAAACATGC AAGTGTCTCAATTTAAAATGGTGAATTACTCCTATGA $\begin{array}{lllllllllllllllll}P & E & N & M & Q & V & S & Q & F & K & M & V & N & Y & S & Y & D\end{array}$ 301 TGAAGATCTGGAAGAGCTTTGTCCCGTGTGTGGAGATA

$$
\begin{array}{llllllllllllllllll} 
& \mathrm{E} & \mathrm{D} & \mathrm{L} & \mathrm{E} & \mathrm{E} & \mathrm{L} & \mathrm{C} & \mathrm{P} & \mathrm{V} & \mathrm{C} & \mathrm{G} & \mathrm{D}
\end{array}
$$

\section{LRH-1 V5}

Exon $2 \mathrm{~b}$

1 AGCCTCCCGCCCCGCGCGGGCGCGGGAGTAGCCCCGCTGGGCGCTCGCAG

51 CCGCGGGAGTCAAGCCCCCTCCCCAGGTGCAGGCATAAAAGTTTATGGCT

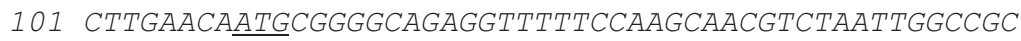

151 TTCTAATTAAGGAAAGAGAGGCTTCCAGCTCTATGGCAACCCAAGCAGGG

\begin{tabular}{llllll}
$M$ & $A$ & $T$ & $Q$ & $A$ & $G$ \\
\hline
\end{tabular}

Exon 3

201 CAgCTTCAgGCTA AAgTGTCTCAATTTAAAATGgTGAATTACTCCTATGA

$\begin{array}{llllllllllllllllll}\mathrm{Q} & \mathrm{L} & \mathrm{Q} & \mathrm{A} & \mathrm{K} & \mathrm{V} & \mathrm{S} & \mathrm{Q} & \mathrm{F} & \mathrm{K} & \mathrm{M} & \mathrm{V} & \mathrm{N} & \mathrm{Y} & \mathrm{S} & \mathrm{Y} & \mathrm{D}\end{array}$

251 TGAAGATCTGGAAGAGCTTTGTCCCGTGTGTGGAGATA

$\begin{array}{lllllllllllllllll} & \text { E } & D & L & E & E & \text { L } & C & \text { P } & \text { V } & \text { C } & \text { G } & \text { D }\end{array}$ 


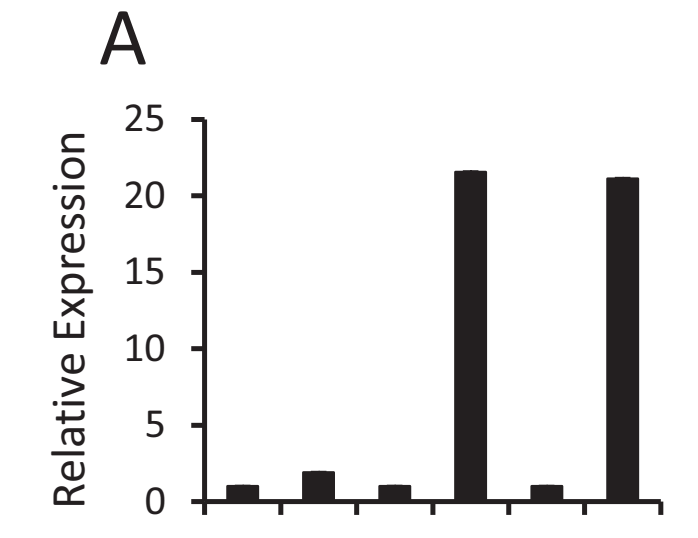

$$
\frac{N L \quad E 2}{V 1 / V 2} \frac{N L \quad E 2}{V 4} \frac{N L \quad E 2}{V 5}
$$
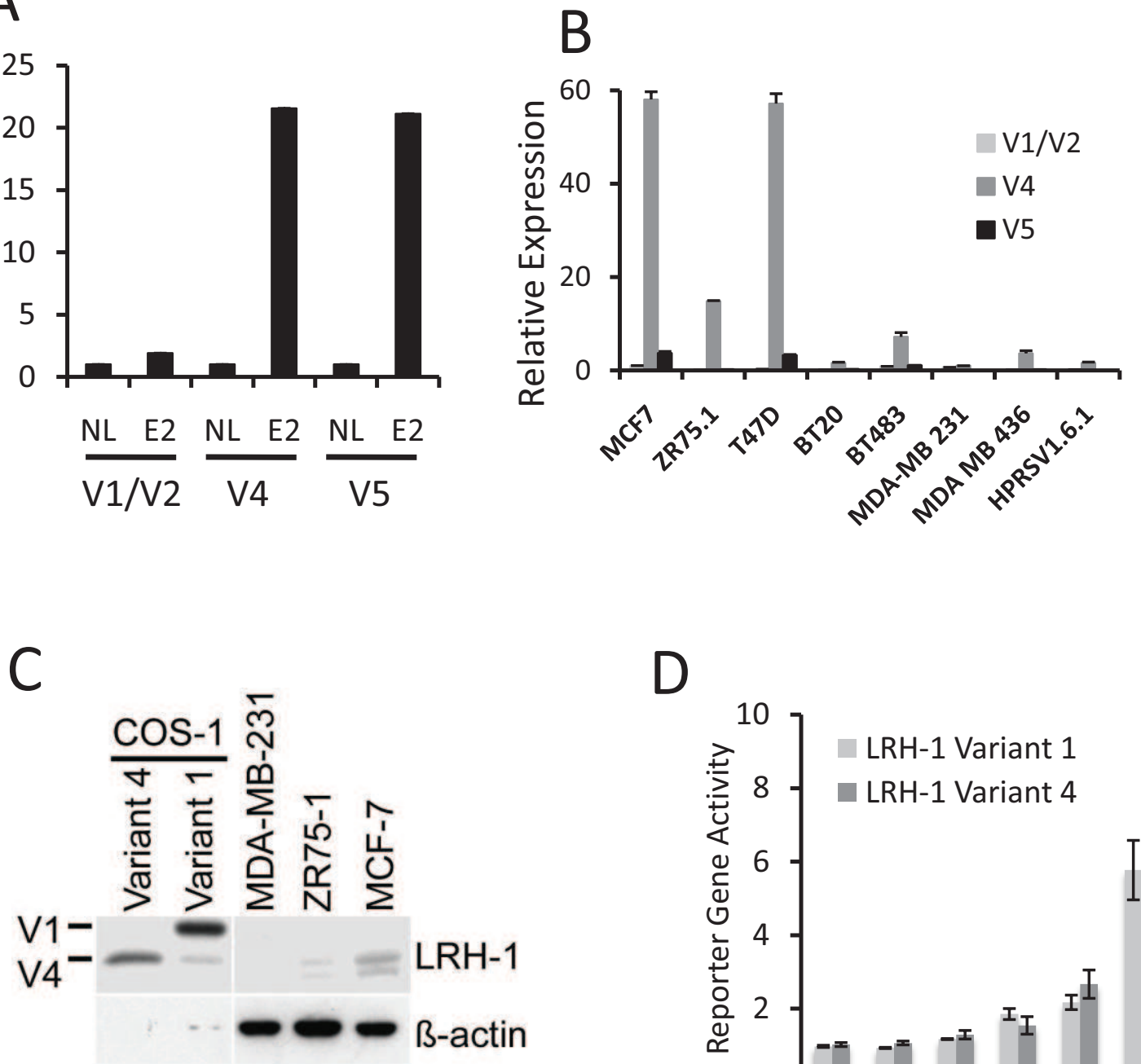

D

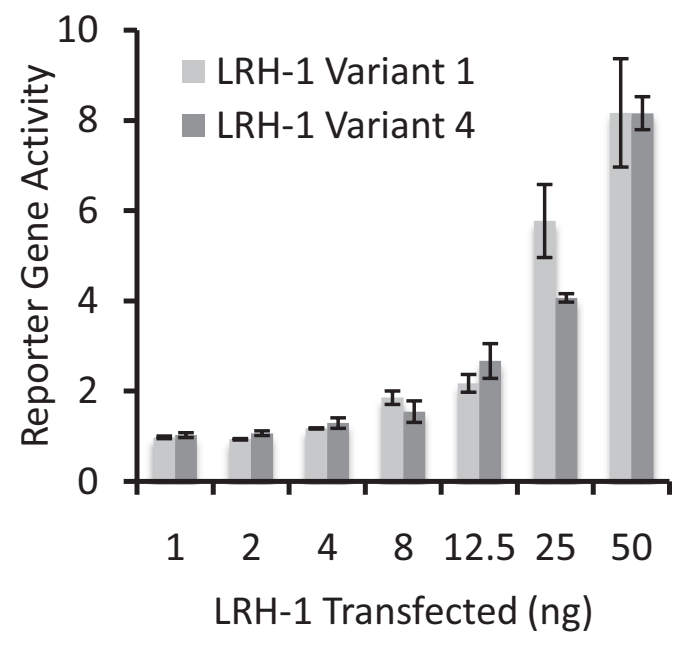

LRH-1 Variant 1 (ng) LRH.1 Variant 4 (ng)

$0 \quad 1 \quad 2 \quad 4 \quad 812.52550 \quad 0 \quad 1 \quad 2 \quad 4 \quad 81252550$

LRH-1

B-actin - - - - - - - - - - - - 

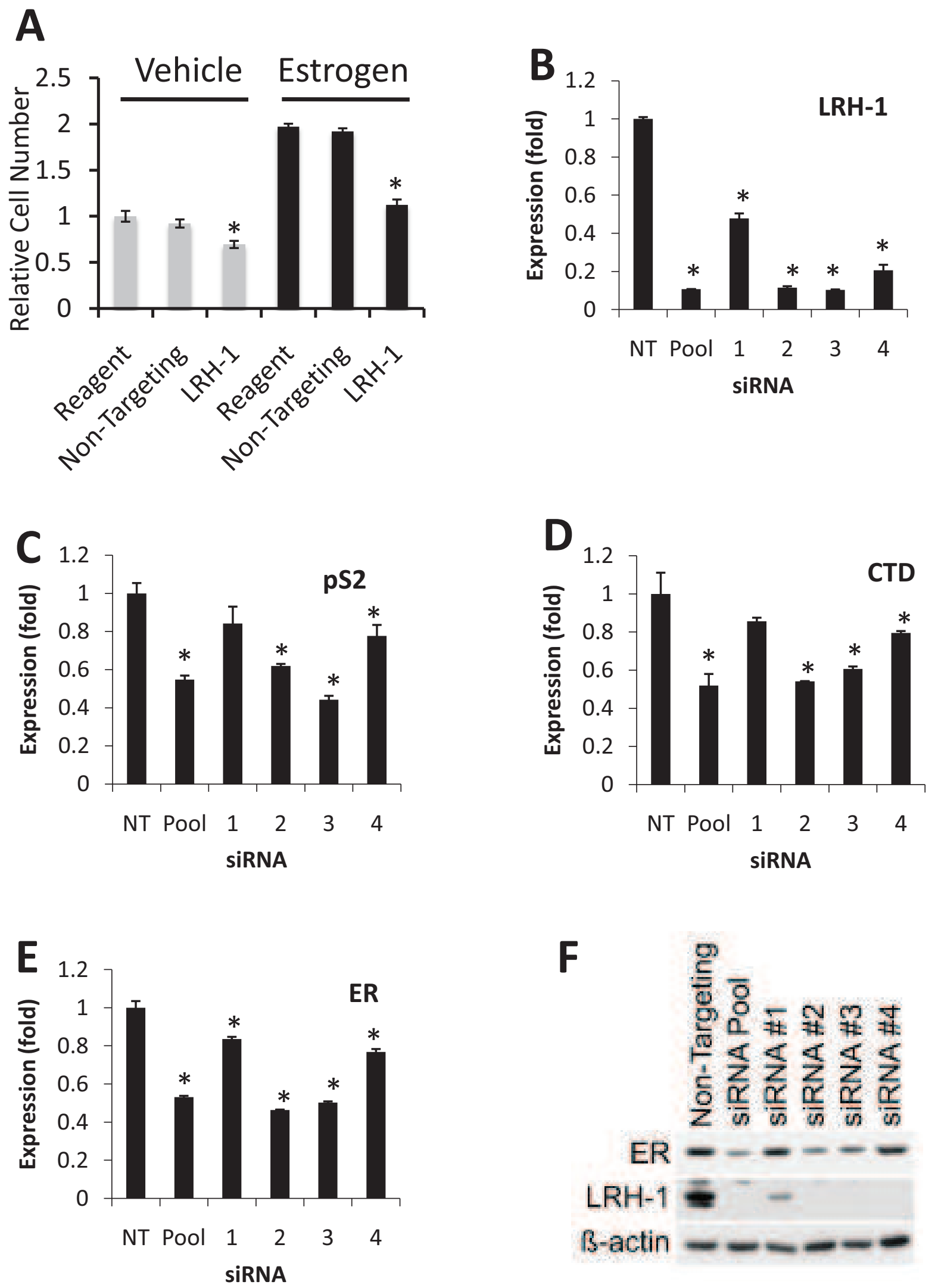


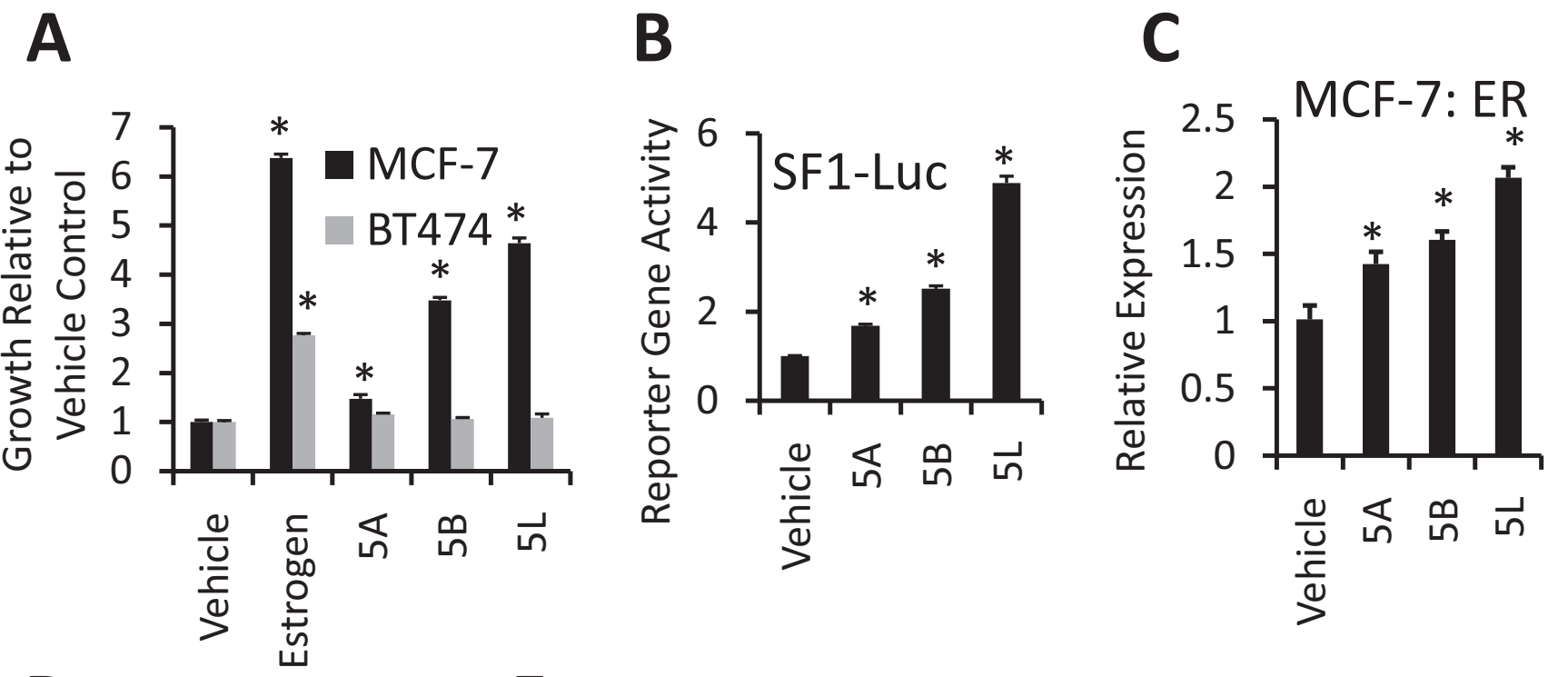

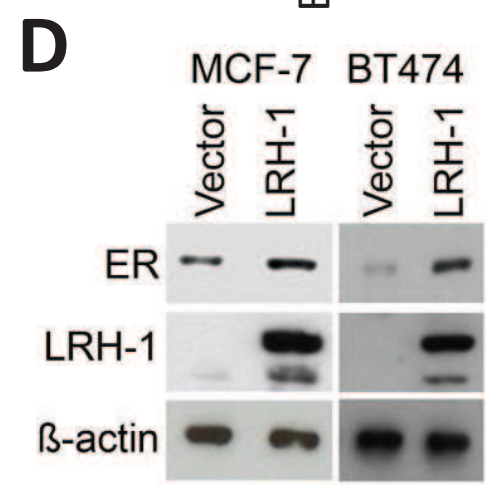

G

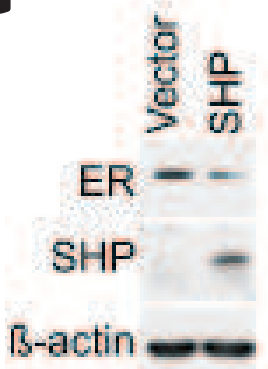

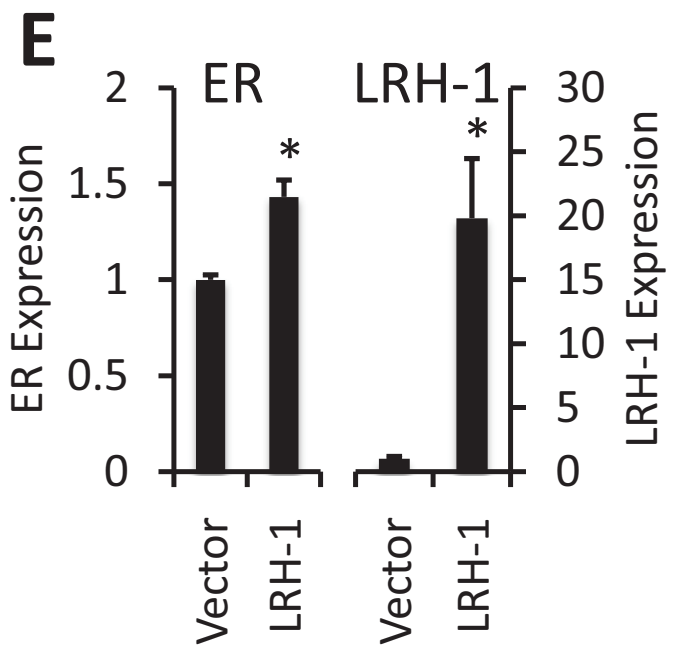

H

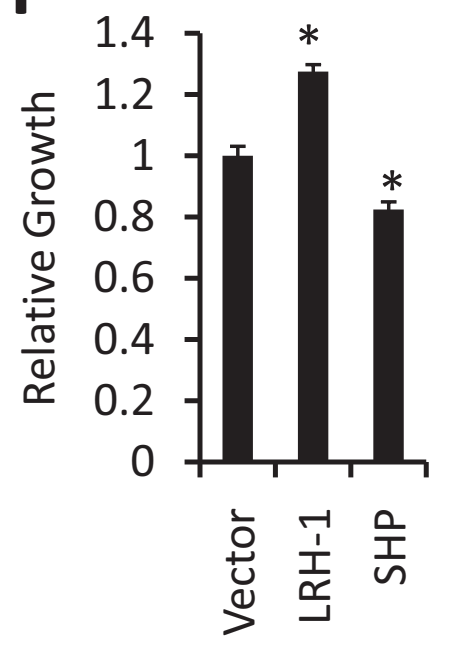


Figure 6

Click here to download Figure: Thiruchelvam et al Figure_6.pptx
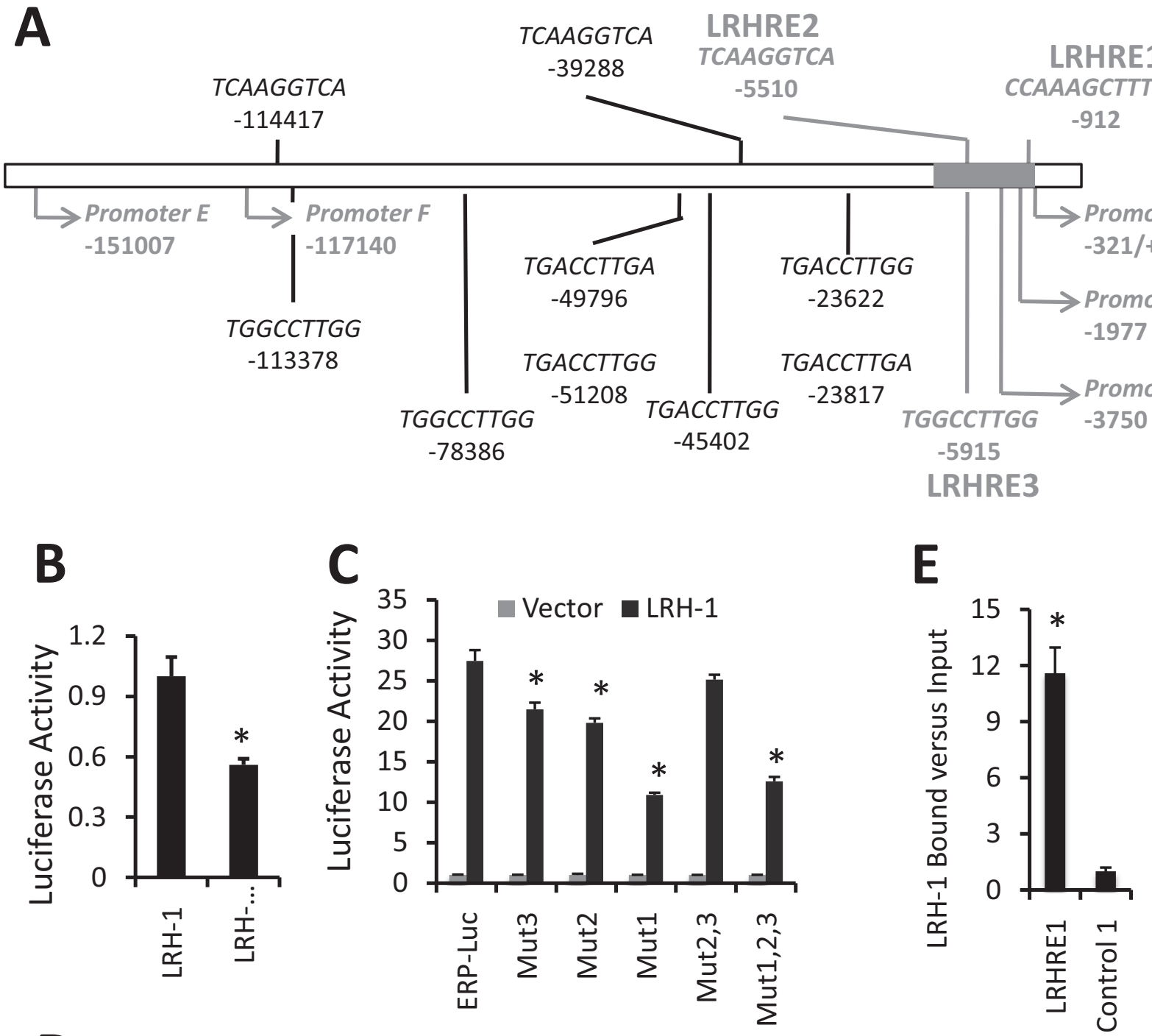

D TGGCCTTGG $-78386$
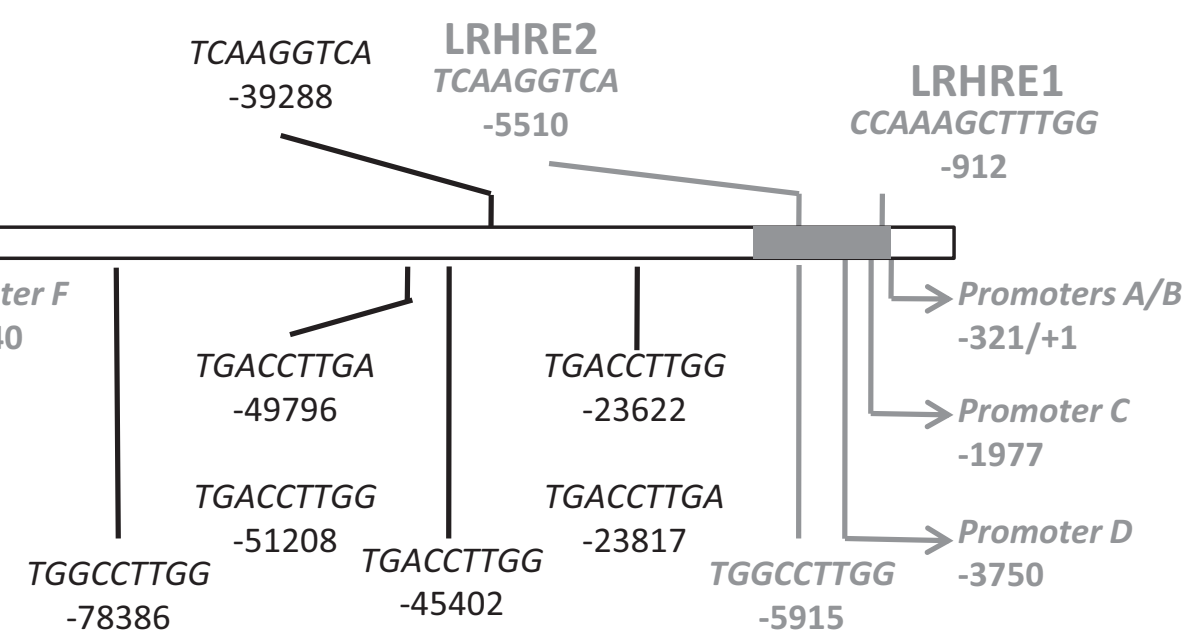

\section{LRHRE3}

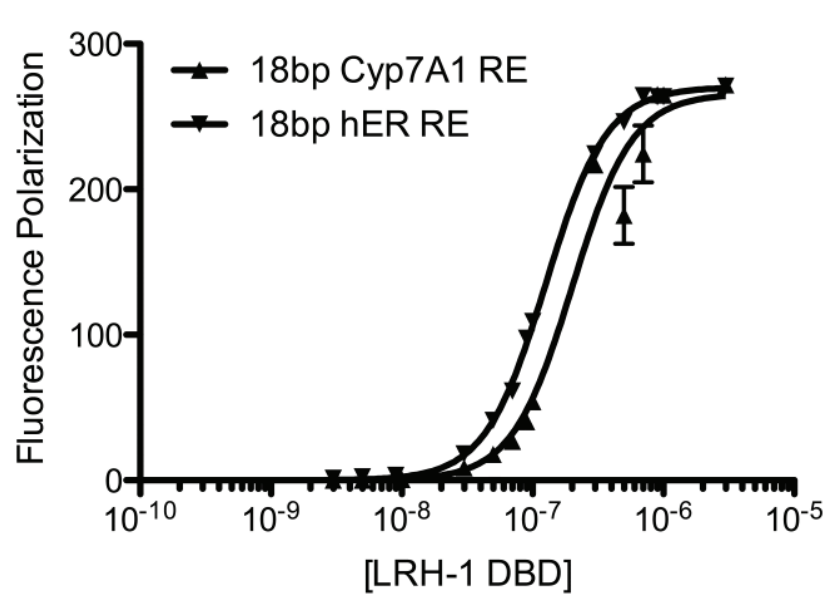

